\title{
BAIRRO BOSQUE DE PRESIDENTE PRUDENTE/SP - LEITURA SÓCIO ESPACIAL
}

\author{
Mariane Celeste, Michelle Fernandes, Adriana Hashinaga, Yeda Ruiz Maria
}

Universidade do Oeste Paulista - UNOESTE. Curso de Arquitetura e Urbanismo, Presidente Prudente - SP. E-mail: yedarm@hotmail.com

\section{RESUMO}

Em cidades medias ou cidades intermediarias como é o caso de Presidente Prudente, é comum os centros se fragmentarem e virarem subcentros. Porém ainda existem bairros como o bairro Bosque que dependem de seus bairros vizinhos, pois não são auto sustentáveis. 0 morador refere-se ao seu bairro, quando quer situar-se na cidade; tem a impressão de ultrapassar um limite quando vai a um outro bairro. É com base no bairro que se desenvolve a vida pública, que se organiza a representação popular. Finalmente, e não é o menos importante, o bairro tem um nome que lhe confere uma personalidade dentro da cidade. Neste contexto o presente trabalho tem como objetivo analisar as características físicas e sociais do Bairro Bosque localizado no município de Presidente Prudente-SP.

Palavras-chave: Bairro. Subcentro. Bairro Bosque. Presidente Prudente-SP.

\section{DISTRICT PRESIDENT OF GROVE SAGE / SP - SOCIAL READING SPACE}

\begin{abstract}
In medium cities or intermediate cities as is the case of Presidente Prudente, it is common for centers to fragment and turn subcenters. But there are still neighborhoods like Bosque neighborhood who depend on their neighborhoods, they are not self-sustaining. The resident refers to his neighborhood when he wants be in the city; has the impression exceed a limit when going to another neighborhood. It is based in the neighborhood that develops public life, which organizes the popular representation. Finally, and not least, the neighborhood has a name that gives it a personality within the city. In this context, this article aims to analyze the physical and social characteristics of Grove Subdivision in the city of Presidente Prudente-SP.
\end{abstract}

Keywords: Neighborhood. Subcentre. Bosque neighborhood. Presidente Prudente-SP. 


\section{INTRODUÇÃO}

Em cidades medias ou cidades intermediarias como é o caso de Presidente Prudente, é comum os centros se fragmentarem e virarem subcentros. Porém ainda existem bairros como o bairro Bosque que dependem de seus bairros vizinhos, pois não são auto sustentáveis. Segundo Lefebvre (1975), o bairro só pode ser definido a partir da cidade entendida como totalidade. Ou seja, o bairro não existe como uma unidade isolada e autônoma. O bairro sendo um espaço físico e social caracteriza-se em constante metamorfose, e assim precisando de estudo e planejamento, pois um bairro possui passado, presente e futuro.

De acordo com George (1983), o bairro é a unidade de base da vida urbana. O morador refere-se ao seu bairro, quando quer situar-se na cidade; tem a impressão de ultrapassar um limite quando vai a um outro bairro. É com base no bairro que se desenvolve a vida pública, que se organiza a representação popular. Finalmente, e não é o menos importante, o bairro tem um nome que the confere uma personalidade dentro da cidade (GEORGE. 1983). Sendo assim, o bairro do Bosque nada mais é que uma delimitação subjetiva de um território, feita pela população, podendo ser também referenciados fora dos limites administrativos. A sociedade define essa delimitação mentalmente, quando se trata de um bairro, que pode ser definido como um espaço que atende as necessidades dos moradores que lá estão, e as vezes, estes locais não estão inseridos no mapa administrativo.

Neste contexto o presente trabalho tem como objetivo analisar as características físicas e sociais em geral, as polemicas envolvidas e sua transformação, sua localização próxima ao centro e seus acessos, a significância social que também passou por transformações ao longo do tempo, seu espaço publico e privado, que é uma das problemáticas levantadas para intervenção, juntamente com a praça e elementos urbanos que foi constatado de situação precária.

Nesse trabalho foi feito uma breve análise do bairro Bosque através de pesquisas em jornais antigos, escrituras fornecidas pela prefeitura, mapas e entrevistas semi-estruturadas com moradores. Os dados obtidos foram através de análises documentais e/ou subjetivas.

\section{BAIRRO BOSQUE - ESTUDO DE CASO}

O Bairro do Bosque fica localizado entre as Vilas Marcondes, Vila Comercial, Vila Maristela, etc. Além de ficar próximo ao centro, ele é considerado como um bairro de apoio ao centro pois, devido ao grande crescimento comercial, o centro, começou a não suprir mais sozinho, precisando ter bairros de apoio que prolongam com várias empresas. O Bosque para seus moradores é considerado como parte do centro da cidade. 
A localização do Bairro Bosque é privilegiada. Seus acessos principais ficam por conta das avenidas Washington Luiz, Cel. José S. Marcondes, Brasil e Getúlio Vargas. Os pontos de referencia mais comuns são a Apea. a antiga Biblioteca Municipal, que hoje é a sede da Secretaria da Saúde Municipal, a E.E. Fernando Costa - IE, bem como o Colégio Cristo Rei.

O Bairro do Bosque surgiu em finais da década de 1940, envolvendo uma grande polêmica: a derrubada de uma grande área de aproximadamente $48.000 \mathrm{~m}^{2}$ de vegetação arbórea nativa, conhecida como "Bosque Municipal". Em finais desta década, a área foi vendida, desrespeitando o seu caráter público e, após disputas judiciais, a propriedade finalmente foi entregue a seu comprador e posteriormente loteada. A reserva foi devastada e o bosque desapareceu por completo, cedendo lugar a um loteamento urbano; hoje conhecido como bairro do Bosque (DENARI, 2013).

Por muitos anos o Bosque foi um bairro quase que exclusivamente residencial, aos poucos foi perdendo essa característica e surgiram alguns pontos comerciais. Por volta de 1962, o Bairro Bosque foi asfaltado e algumas residências se transformaram em escritórios, fatos estes que sanaram a saturação do centro da cidade que já não estava mais comportando todos os negócios necessários (FILHO, 1999). Ao longo do tempo a delimitação geofísica do Bairro Bosque sofreu alterações significativas, tendo ainda hoje uma diferenciação dos limites administrativos, de levantamento mundial (Maps) e o levantamento in loco.

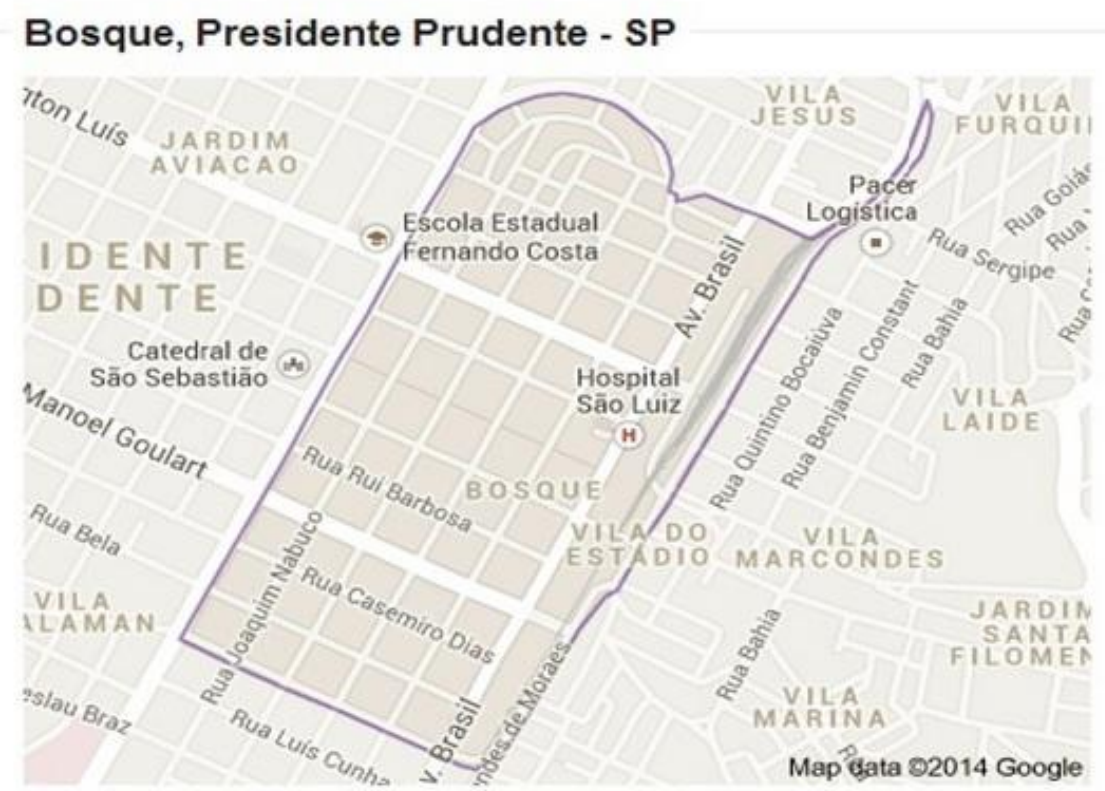

Figura 1. Mapa da delimitação do bairro do Bosque.

Fonte: Google Maps. 
A imagem acima mostra uma delimitação física do bairro do Bosque equivocada, seu limite na verdade é menor do que mostra a imagem 1.

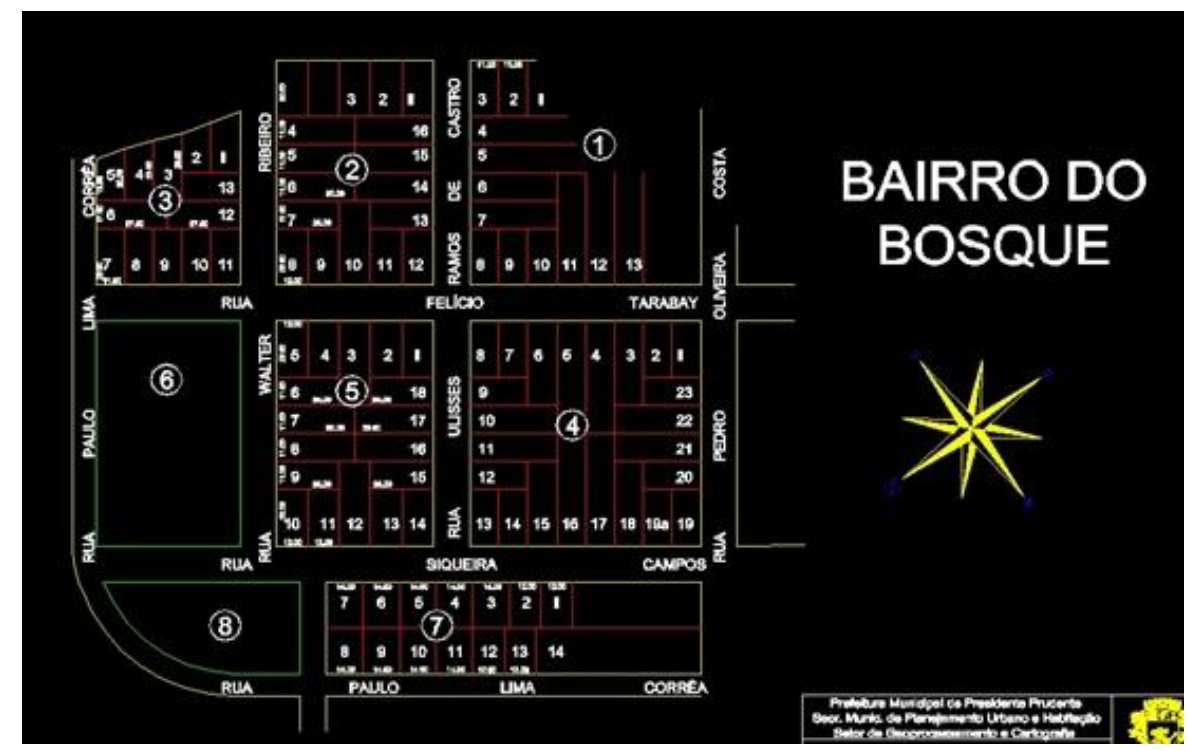

Figura 2. Planta baixa do bairro do Bosque.

Fonte: Prefeitura de Presidente Prudente.

Observa-se abaixo a imagem 3 de um levantamento in loco feito pelo grupo, e como maior diferença, temos a desobstrução da Rua Ulisses Ramos de Castro, criando assim a Rua Desbravador Ceará, que por consequência criou um problema de planejamento, pois a delimitação de começo e fim é apenas administrativa, causando confusão nos civis que as utilizam.

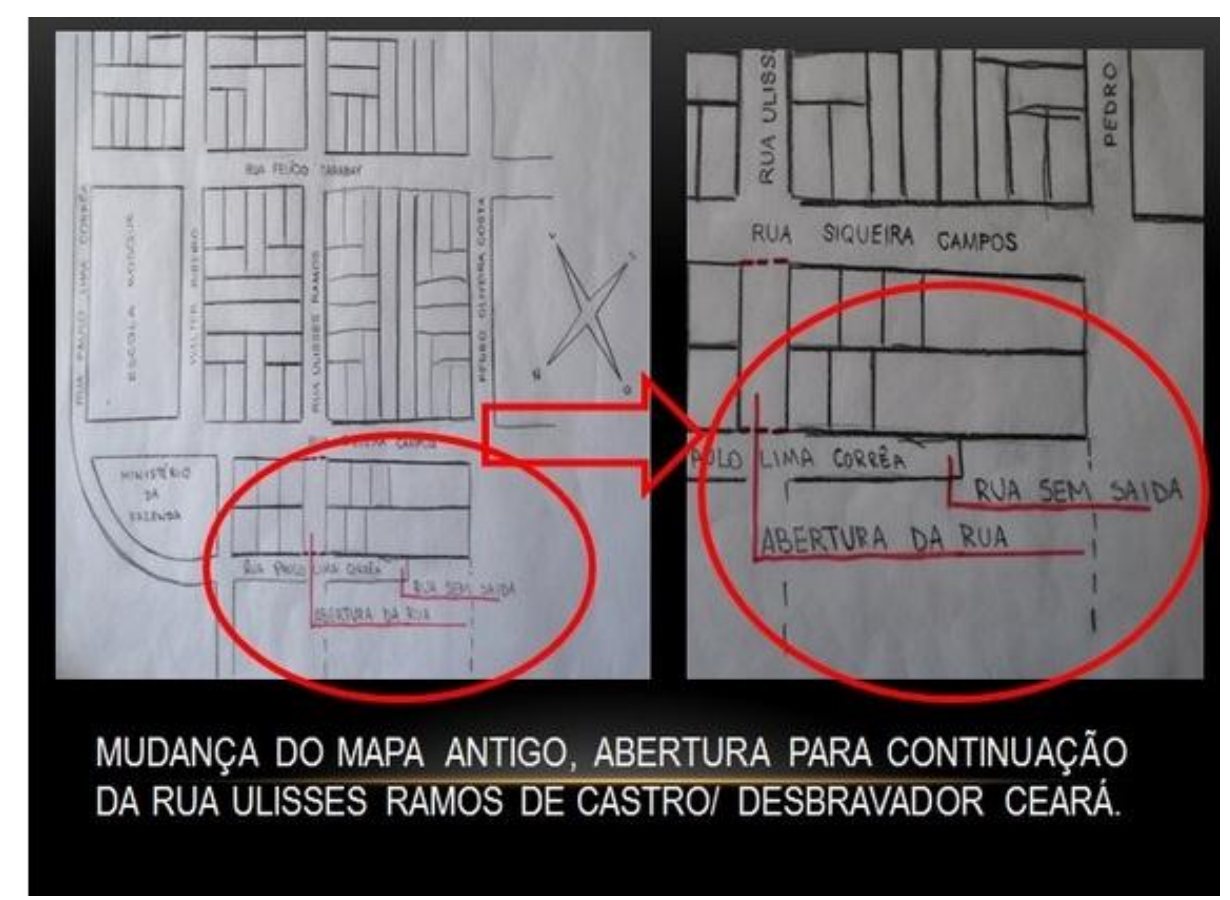

Figura 3. Croqui do bairro do Bosque.

Fonte: Próprio autor. 
Hoje, o Bosque é um "braço do centro", ou seja, sua utilização é de apoio para as atividades do centro da cidade, suas ruas são usadas para estacionamento de automóveis de pessoas que trabalham no centro, ou se utilizam do mesmo, embora seu planejamento tenha sido para um bairro residencial, hoje é usado como um bairro-apoio, e lamentavelmente, sem a estrutura mínima necessária; ruas estreitas com carros estacionados em ambos os lados, dificultam o tráfego; uma rua, em especial, é sem saída, se tornou perigosa para manobras dos carros, rua essa que provém de intervenções mal pensadas, as quais foram feitas em tentativa de "remendo" de problemas evitáveis.

Construções antigas são comuns naquela região, normalmente ao estilo dos anos 40, 50 e 60. São casas e sobrados que embelezam o bairro e lhe dão imponência, culminando por preservar a história. Antigamente o Bairro do Bosque era de alto padrão, chegando a ser habitado pelo prefeito Florivaldo Leal e pelo Comendador José Lemes Soares; hoje se trata de um bairro de classe média com edificações de estilo colonial, muitas delas já reformadas, outras abandonadas. Por ser um bairro histórico foi perdendo a sua significância social. Por conter muitos moradores idosos, que habitam aquele lugar á mais de 30 anos, a maioria das casas são velhas e não passaram por reforma alguma, seguindo os padrões de antigamente.

Segundo RAMOS, A. W. (2002, p.66), "o bairro também pode ser entendido como uma mediação entre o espaço privado (da casa, da família) e o público, entre a vida familiar e as relações societárias mais amplas. De tal forma que o bairro é o locus de uma sociabilidade intermediária, como o espaço do encontro, construído no nível da vida cotidiana." Assim, o bairro do Bosque inicialmente possuía caráter público, com espaços de passeios e vida coletiva, este item da análise é deveras polêmico; hoje como um bairro residencial o Bosque foi loteado, perdendo sua característica coletiva.

Como resquício de coletividade encontra-se uma pequena praçaao lado da Secretaria da Fazenda, entretanto por falta de planejamento adequado sua utilização pelos moradores é mínima; se trata de um espaço público, mas não possui dinâmica coletiva.

A Rua Paulo Lima Corrêa, não possui saída, e é uma das polêmicas Pública/Privada, pois pode ser considerada como uma privatização do espaço público, quando analisado o tráfego de automóveis naquele espaço, que é utilizado praticamente pelos moradores daquele local; entretanto pode-se também considerar como um espaço público, já que existem serviços de comércio naquele local.

A praça do Bairro Bosque era totalmente arborizada, deixando o local ao anoitecer muito perigoso e escuro. Os moradores fizeram um abaixo assinado exigindo mudanças na praça. A 
prefeitura acabou cedendo e reformando a praça, foram tiradas muitas das árvores e plantadas outras espécies que dariam maior visibilidade aos moradores ao anoitecer. A praça ganhou aparelhos da academia de idosos com intuito de atrair os próprios moradores antigos a utilizá-lo. Porém não foi muito bem planejada, pois não se foi pensado nesta reforma o conforto da praça, o sol incide durante o dia inteiro nestes aparelhos, impedindo que alguém o utilize devido estar muito quente por ser de material de ferro.

É possível identificar que a iluminação do bairro é precária, tendo ruas com árvores grandes que também prejudicam a iluminação durante a noite, motivo de reclamação dos moradores. 0 bairro é muito movimentado durante o dia, pois pessoas que trabalham no centro param seus carros no Bairro Bosque, fugindo da zona azul que é obrigatória nas ruas centrais, assim as ruas do bairro ficam cheias de carros de ambos os lados, prejudicando os próprios moradores que reclamam da via ficar muito estreita e muito movimentada.

Há placas que por vezes não são vistas por quem passa pelo local, como a placa de rua sem saída, que muitas vezes não é vista e muitos motoristas entram na rua por engano e, ao ver que não ter saída, voltam à rua anterior. Sinalização horizontal e vertical como também acessibilidade estão mais presentes no entorno da escola por ser de responsabilidade da mesma.

\section{CONCLUSÃO}

Neste trabalho abordamos em geral o histórico e social do bairro do Bosque, através de análises documentais, onde foi levantado suas problemáticas. Constatamos que o bairro é carente de espaços de integração da população local e devido ao bairro estar localizado ao lado do centro, há um grande fluxo de carros, onde muitos deles estacionam de ambos lados da via, tornando a passagem estreita, ocasionando uma má organização do fluxo.

A praça é uma das maiores problemáticas do bairro, devido à um planejamento deficitário em relação à sua reorganização. Foram retiradas as árvores antigas pelo fato destas não permitirem a iluminação, tornando a praça perigosa, implantando outro tipo de vegetação e a academia da terceira idade, porém não foi pensado na disposição da insolação no local principalmente sobre os aparelhos.

Esse trabalho foi de grande importância para nosso conhecimento, compreendemos melhor o funcionamento e transformação do bairro de estudo, pois para melhorar um espaço é necessário conhecê-lo e entendê-lo primeiramente. 


\section{REFERÊNCIAS}

DENARI, Zelmo. Defesa do patrimônio histórico. O Imparcial. Presidente Prudente, Jun. 2013, História.

FILHO, A.C. Bosque está se tornando num bairro comercial. O Oeste Paulista. Presidente Prudente, 31 jan.1999. Local. 2F.

GEORGE, P. (1983) Geografia urbana. Tradução Grupo de Estudos Franceses de Interpretação e Tradução. São Paulo, Difel. p. 236.

LEFEBVRE, H.. Barrio y vida de barrio. In: De lo rural a lo urbano. 3. ed. Barcelona:

Ediciones Península, 1975, p. 195-203.

RAMOS, A.W. (2002) Espaço-tempo na cidade de São Paulo: historicidade e espacialidade do "bairro" da Água Branca. Revista do Departamento de Geografia, n.15, p. 65-75.

SOLLER, Geraldo. O Imparcial. Presidente Prudente, 20 mar.2002. Fotos e Fatos. 